\title{
CDKN1A Gene Mutation
}

National Cancer Institute

\section{Source}

National Cancer Institute. CDKN1A Gene Mutation. NCI Thesaurus. Code C150475.

A change in the nucleotide sequence of the CDKN1A gene. 